\title{
REDUCTIVE MOBILIZATION OF OXIDE-BOUND METALS
}

THE U.S. DEPARTMENT OF ENERGY, AGREEMENT NO. DE-FG02-90ER60946

\author{
Progress Report \\ for the Period September 15, 1991 - September 15, 1992 \\ DOE/ER/60946--3 \\ Alan T. Stone \\ DE93 003159 \\ Department of Geography and Environmental Engineering \\ G.W.C. Whiting School of Engineering, The Johns Hopkins University \\ Baltimore, Maryland 21218
}

This project is concerned with the mobilization of $\mathrm{MnO}_{2}$ - and $\mathrm{FeOOH}$-bound toxic metals in subsurface environments arising from an influx of natural organic matter or organic-containing wastes. Our work to date emphasizes the importance of characterizing the reductant, complexant, and adsorptive characteristics of constituent organic chemicals. Organic chemicals may interact with pollutant metals directly, or may bring about changes in speciation and solubility indirectly by acting upon $\mathrm{MnO}_{2}$ and $\mathrm{FeOOH}$ host phases. The primary application of this work is the understanding of metal sorption and release processes within subsurface environments undergoing changes in redox status.

\section{Release of $\mathrm{MnO}_{2}$-Bound Toxic Metals}

In September 1991 we reported that a major set of experiments had been completed which examined the release of $\mathrm{MnO}_{2}$-bound $\mathrm{Co}, \mathrm{Ni}$, and $\mathrm{Cu}$ by representative low $\mathrm{MW}$ reductants and complexants (hydroquinone, pyruvate, oxalate, citrate, acetoin) and by natural organic matter samples. Oxalate and citrate are especially important, because of their widespread use as nuclear reactor decontamination reagents (Sellers, 1983).

A great deal of work was completed during the past year evaluating the results of these experiments and preparing the work for publication. A Ph.D. thesis based upon this work (Godttredsen, 1991) was accepted in March. A manuscript entitled "Release of $\mathrm{MnO}_{2}$ Bound Copper by Naturally-Occurring Organic Compounds" is ready for submission to the British journal Nature; drafts of two additional manuscripts are nearing completion.

\section{Release of FeOOH-Bound Toxic Metals (l)}

Our experimental work now focuses upon the sorption of $\mathrm{Fe}(\mathrm{II}), \mathrm{Co}, \mathrm{Cu}$, and $\mathrm{Pb}$ onto iron(III) oxides, and their subsequent release in response to changes in aqueous phase chemistry. Our work in this area emphasizes the four areas listed below.

(1) Sorption/desorption of toxic metals. Before work on more complex systems can be attempted, metal sorption equilibria must understood. Quantitative modelling efforts are applied to iron(III) oxide suspensions containing a single metal and to suspensions containing two or more metals.

(2) Simultaneous consideration of sorptive and complexant characteristics of organic compounds. Unlike manganese(IV) oxides, iron(III) oxides sorb significant quantities of carboxylic acids and other organic compounds possessing ligand donor groups. Complexation of metals by dissolved organic compounds provides a driving force for metal release; complexation of metals by sorbed, multidentate organic compounds provides a driving force for increased retention (ternary complex formation).

(3) Evaluating the dual role of organic compounds as complexants and as reductants. Iron(III) oxides aire significantly weaker oxidants than manganese(IV) oxides in a 


\section{DISCLAIMER}

This report was prepared as an account of work sponsored by an agency of the United States Government. Neither the United States Government nor any agency thereof, nor any of their employees, makes any warranty, express or implied, or assumes any legal liability or responsibility for the accuracy, completeness, or usefulness of any information, apparatus, product, or process disclosed, or represents that its use would not infringe privately owned rights. Reference herein to any specific commercial product, process, or service by trade name, trademark, manufacturer, or otherwise does not necessarily constitute or inply its endorsement, recommendation, or favoring by the United States Government or any agency thereof. The views and opinions of authors expressed herein do not necessarily state or reflect those of the United States Government or any agency thereof. 
thermodynamic sense. Despite this fact, several candidate organic complexants (including oxalate and citrate) are known to reduce iron(III) oxides. Under acidic $\mathrm{pH}$ conditions, redox reaction is evident from the appearance of $\mathrm{Fe}(\mathrm{II})$ in overlying solution. Under neutral and alkaline $\mathrm{pH}$ conditions, $\mathrm{Fe}(\mathrm{II})$ is retained by the remaining oxide, and may facilitate toxic metal release. Combined reductant/complexant mixtures are much more effective at bringing about the reductive dissolution of iron(III) oxides than reductants alone (dos Santos Afonso et al., 1990).

Contact of $F e(I I)$ with iron(III) oxides generates mixed-valence oxides (Tronc et al., 1992); these surface chemical changes may influence the sorption of toxic metals and complexant organic compounds. Upon the onset of reducing conditions, the surface chemistry of mixed $\mathbf{A}$ (III)-Fe(III) oxides may evolve differently than pure $\mathrm{Fe}$ (III) oxides; $\mathbf{A}$ (III) remaining on the surface may armor particles and prevent further dissolution.

(4) Coordination chemistry and toxic metal release. $\mathrm{Pb}(\mathrm{II})$ is a classic "soft" metal, while $\mathrm{Fe}(\mathrm{II}), \mathrm{Co}(\mathrm{II})$, and $\mathrm{Cu}(\mathrm{II})$ are "borderline" metals. Organic complexants possessing nitrogenor sulfur-donor substituents are therefore expected to yield greater $\mathrm{Pb}$ release than more abundant oxygen-donor complexants.

\section{Release of FeOOH-Bound Toxlc Metals (II)}

The U.S. Drinking Water Standard $\left(2.4 \times 10^{-8} \mathrm{M}\right.$ for $\left.\mathrm{Pb}\right)$ provides a benchmark for evaluating metal toxicity. We now employ graphite-furnace atomic absorption spectrophotometry (AAS) in order to reach this analytical range, and flame AAS to cover higher concentrations. The BPDS colorimetric method makes it possible for us to reliably distinguish between $\mathrm{Fe}$ (II) and $\mathrm{Fe}$ (III) in filtered solutions.

FeOOH (type $\alpha$ ) has been synthesized and characterized for use in our experiments. In most instances, a loading of $1.0 \mathrm{~g} / \mathrm{L}$ is employed, which corresponds to a BET area loading of $48 \mathrm{~m}^{2} / \mathrm{L}$ and a fluoride-binding surface site concentration of $2.3 \times 10^{-4} \mathrm{M}$.

Our last report discussed at length the use of flow-through reaction systems for studying toxic metal retention and release by iron oxides. We discussed our plans extensively with Prof. Donald Sparks (University of Delaware), Prof. Charles O'Melia (Johns Hopkins University) and others. As our ideas matured, we felt that the batch experiments provide the most immediate and straightforward means of obtaining partitioning parameters and kinetic information important for meeting the goals of this project. In the future we would like to collaborate with researchers at PNL and other laboratories to place our work in the context of flow-through environments.

Time studies in our laboratory indicate that $\mathrm{Cu}$ and $\mathrm{Pb}$ adsorption onto $\mathrm{FeOOH}$ reaches quasi-equilibrium within 18 hours of contact time. Adsorption isotherms have been performed at $\mathrm{pH} 4.9$ covering a four order-of-magnitude increase in $\mathrm{Cu}$ and $\mathrm{Pb}$ concentrations (Figure 1). Linearized forms of the Langmuir Equation can be used to calculate adsorption constants $\left(K^{8}\right)$ and maximum adsorption densities $\left(S_{T}\right)$ from the experimental data. The low concentration data $(0.050$ to $0.70 \mu \mathrm{M})$ yield $K^{6}$ values that are substantially greater than those obtained from the high concentration data $(5.0$ to $3000 \mu \mathrm{M})$. This is an indication that the $\mathrm{FeOOH}$ surface sites are not uniform; a subset of sites exhibits higher affinity for toxic metals. An adsorption "edge" is observed near pH 4.8, as shown in Figure 2.

A major goal of this work is to assess the importance of toxic metal sorption onto iron oxides under conditions of changing redox status. To meet this objective, it is important to establish whether Fo(ii) produced by the reduction of $\mathrm{FeOOH}$ directly competes with toxic metals for surface sites and whether adsorbed $\mathrm{Fe}$ (II) alters the reactivity or adsorptive properties of $\mathrm{FeOOH}$.

The adsorption of $\mathrm{Fe}(\mathrm{II})$ onto $\mathrm{FeOOH}$ has been measured in our laboratory. Great 
care was taken to exclude $\mathrm{O}_{2}$ from the reactor system, to ensure that autoxidation does not take place; experiments were performed in an inert-atmosphere glove box. $\mathrm{S}_{\mathrm{T}}$ for $\mathrm{Fe}$ (II) was nearty equal the value obtained for $F$ adsorption, but approx. 2.5 times higher than $S_{T}$ obtained for $\mathrm{Cu}$ and $\mathrm{Pb}$ adsorption. Under comparable conditions $(\mathrm{pH} \mathrm{4.9,} 18$ hours contact time), $\mathrm{K}^{\circ}$ decreased in the following order: $\mathrm{Cu}>\mathrm{Pb}>>\mathrm{Fe}^{\mathrm{l}}$ (Se日 Figure 2).

In our earlier work with $\mathrm{MnO}_{2}$, increases in TOTMn(II) brought about significant release of sorbed Co, Ni, and $\mathrm{Cu}$; $\mathrm{Mn}$ (II) added to the system as $\mathrm{MnCl}_{2}$ and $\mathrm{Mn}$ (II) generated from the reductive dissolution reaction with pyruvate or hydroquinone yielded the same competitive effect. We are interested in whether $\mathrm{Fe}(\mathrm{II})$ sorption onto FeOOH can cause sorbed metal release in an analogous manner.

A set of experiments has been performed in which $0.44 \mu \mathrm{M} \mathrm{Cu}$ (II) and $\mathrm{Pb}$ (II) have been equilibrated at $\mathrm{pH} 4.9$ for 18 hours before addition of 50 to $200 \mu \mathrm{M} \mathrm{Fe(II).} \mathrm{Fe(iI)}$ reached $2.0 \times 10^{-5} \mathrm{M}$, which is $8.7 \%$ of $\mathrm{S}_{\mathrm{T}}$ and fifty times higher than $[\mathrm{Cu}]_{\mathrm{ads}}$ and $[\mathrm{Pb}]_{\mathrm{ads}}$. After 4 hours of reaction time, the extent of metal desorption was negligible; apparently $F \theta$ (II) loadings of this magnitude are not high enough to significantly affect metal sorption.

Several low molecular-weight organic reductants have been evaluated with respect to their ability to reduce $\alpha-F \theta O O H$. Under the conditions employed (Table I), the maximum extent of reduction dissolution was $0.8 \%$, obtained with $5.0 \mathrm{mM}$ acetoin. We cannot at present monitor the oxidation of acetoin. We can, however, monitor the oxidation of hydroquinone to p-benzoquinone; we have used this reaction in the past to generate known amounts of $\mathrm{Mn}(\mathrm{II})$ from $\mathrm{MnO}_{2}$ reduction (Godtfredsen, 1992).

The sorption behavior of $\mathrm{Cu}(\mathrm{II})$ during the reductive dissolution of $\mathrm{F} \theta \mathrm{OOH}$ by $5.0 \mathrm{mM}$ acetoin is presented in Figure 3. The reductive dissolution reaction is relatively independent of $\mathrm{pH} ; \mathrm{Fe}$ (II) production at $\mathrm{pH} 4.9$ and 5.8 is nearly the same. As the figure indicates, no measureable release of $\mathrm{Cu}$ took place.

Table II presents results of a preliminary experiment examining how the addition of representative low MW organic compounds affects $\mathrm{Cu}$ and $\mathrm{Pb}$ sorption. Each metal was equilibrated with $1.0 \mathrm{~g} / \mathrm{L}$ FeOOH for 18 hours prior to organic compound addition.

Significant decreases $(t)$ and increases $(\uparrow)$ in the extent of metal sorption are marked. Two processes are operative here: complexation of metals by dissolved organic compounds decreases sorption, while complexation of metals by FeOOH-bound metals may increase sorption.

\section{Experimental Work for the Remaining Prolect Perlod}

Additional experiments are currently underway which examine how increases in TOTFe(II) influence the extent of $\mathrm{Co}, \mathrm{Cu}$, and $\mathrm{Pb}$ sorption. Introduction of $\mathrm{Fe}\left(\mathrm{NO}_{3}\right)_{2}$ leads to the creation of "sorbed" $\mathrm{Fe}(\mathrm{II})$. We are interested in whether $\mathrm{Fe}(\mathrm{II})$ added in this manner sorbs like other transition metals, or whether it becomes somehow irreversibly sorbed. Addition of organic reductants generates "lattice-bound" $\mathrm{Fe}(\mathrm{II})$, which may be more difficult to displace from the oxide surface. Timescales of sorption/desorption processes are of importance here, and have important consequences for the sorption/desorption of toxic metals present in these systems.

It is critical that we determine the extent of oxalate, citrate, salicylate, ethy'enediamine, and glycine sorption during toxic metal sorption and release. Chemical derivatization/HPLC for measuring environmental levels of carbonyl compounds and amines has been demonstrated by Mopper (1983) and others, and will be employed. One advantage of this approach over conventional radiotracer techniques is that parent organic compounds can be distinguished from partial oxidation proulucts generated by reaction with the FeOOH surface. We plan to examine how the uptake or release of metals from the surface depend upon the surface coverage by representative organic compounds. We also 
plan to examine how the uptake or release of organic compounds is affect by the presence of metals.

Our group has exchanged ideas and information with Lyyuan Liang of Oak Ridge National Laboratories, who is studying the solubillzation of subsurface iron by natural organic matter; Don Girvin at PNL, who is studying redox reactions between EDTAcomplexed Co and manganese oxides; Bill Fish of the Oregon Graduate Institute of Science and Technology, who is studying the adsorption and reaction of chromate; and John Zachara, who is studying how various mineral surfaces and NOM influence metal sorption and redox reactions.

\section{REFERENCES}

dos Santos Afonso, M., P.J. Morando, M.A. Blesa, S. Banwart, and W. Stumm (1990) The reductive dissolution of iron oxides by ascorbate: the role of carboxylate anions in accelerating reductive dissolution, ل لeolloid interface Scil 138, 74-82.

Mopper, K. (1983) Organic chemical dynamics of the mixed layer: measurements of dissolved hydrophilic organics at sea, In: "Dynamic Processes in the Chemistry of the Upper Ocean", J.D. Burton, P.G. Brewer, R. Chesselt Edits., Plenum, NY.

Sellers, R. M. (1983) The radiation chemistry of nuclear reactor decontaminating reagents, Radiat. Phys. Chem., 21, 295-305.

Tronc, E., P. Belleville, J.-P. Jolivet, and J. Livage (1992) Transformation of ferric hydroxide into spinel by Fe" adsorption, Langmuir, 8, 313-319.

\section{PUBLICATIONS(*) AND PRESENTATIONS}

*Godtfredsen, K. L. (1992) Release of $\mathrm{MnO}_{2}-$ Bound Co, Ni, and $\mathrm{Cu}$ by Acidification, Competitive Sorption, Complexation, and Reductive Dissolution, Ph.D. Thesis, The Johns Hopkins University, Baltimore, MD.

*Godtfredsen, K.L. and A.T. Stone "Solubilization of $\mathrm{MnO}_{2}$-Bound Copper by Naturally-Occurring Organic Compounds", (Submitted to Nature, November, 1992).

Stone, A.T. and K.L. Godtfredsen "Mobilization of Oxide-Bound Toxic Metals by Organic Reducing Agents and Complexing Agents", Second International Symposium on Environmental Chemistry, Universidad Nacional Autonoma de Mexico, Mexico City (September 1991).

Godtfredsen, K.L. and A.T. Stone "Mobilization of $\mathrm{MnO}_{2}-$ Bound $\mathrm{Co}, \mathrm{Cu}$, or Ni" [Poster], Interfacial Phenomena in the Environment, an International Symposium in Honor of Werner Stumm, European Environmental Research Organization, Davos, Switzerland (October 1991).

Godtfredsen, K.L. and A.T. Stone "Mobilization of $\mathrm{MnO}_{2}-$ Bound Metals by Organic Reducing Agents and Complexing Agents", Symposium on "Oxidation-Reduction Transformations of Inorganic and Organic Species in the Environment", American Chemical Society National Meeting, San Francisco, CA (April 1992).

Stone, A.T., K.L. Godtfredsen, and B.R. Coughlir, "Solubilization of FeOOH- and $\mathrm{MnO}_{2}$. Bound Metals by Naturally-Occurring Organic Compounds", Symposium on "Surface Chemistry of Natural Materials", Goldschmidt Conference, Geochemical Society, Reston, VA (May 1992).

Stone, A.T., K.L. Godttredsen, and B.R. Coughlin "Mobilization of Oxide-Bound Metals by Naturally-Occurring Complexants and Oxidants", [Poster], "International Society of Soll Science "Impact of Interactions of Inorganic, Organic, and Microbiological Soll Components on Environmental Quality", Edmonton, Alberta (August 1992). 


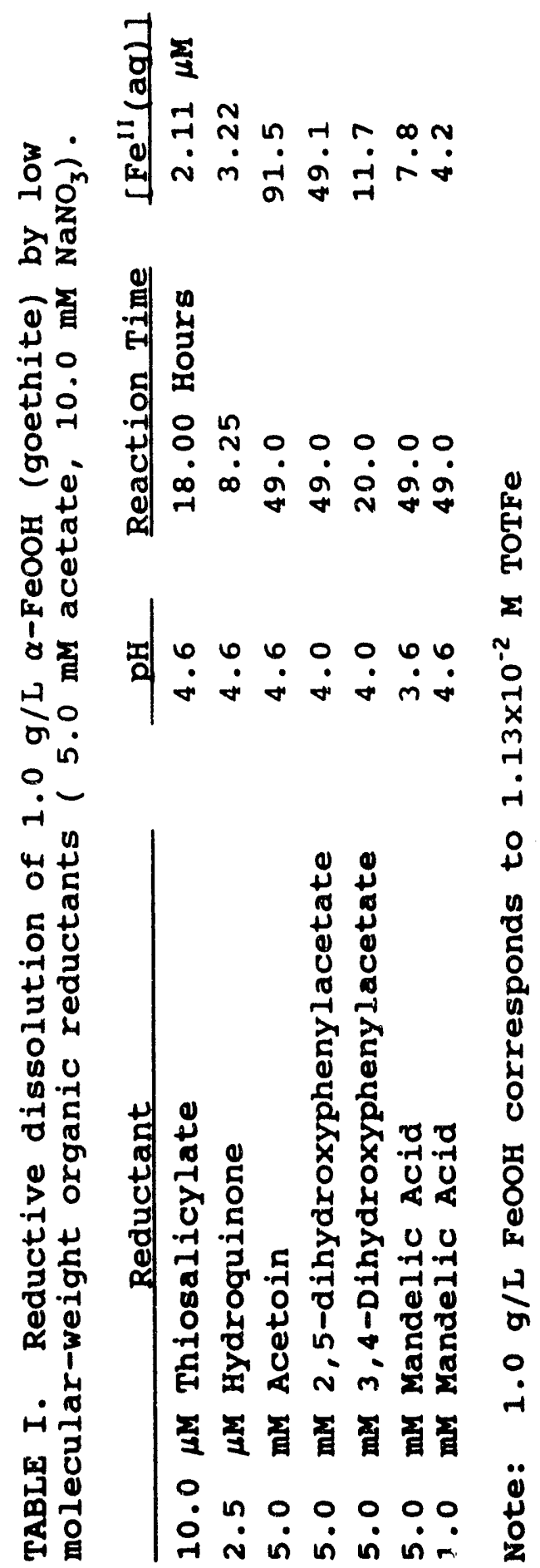

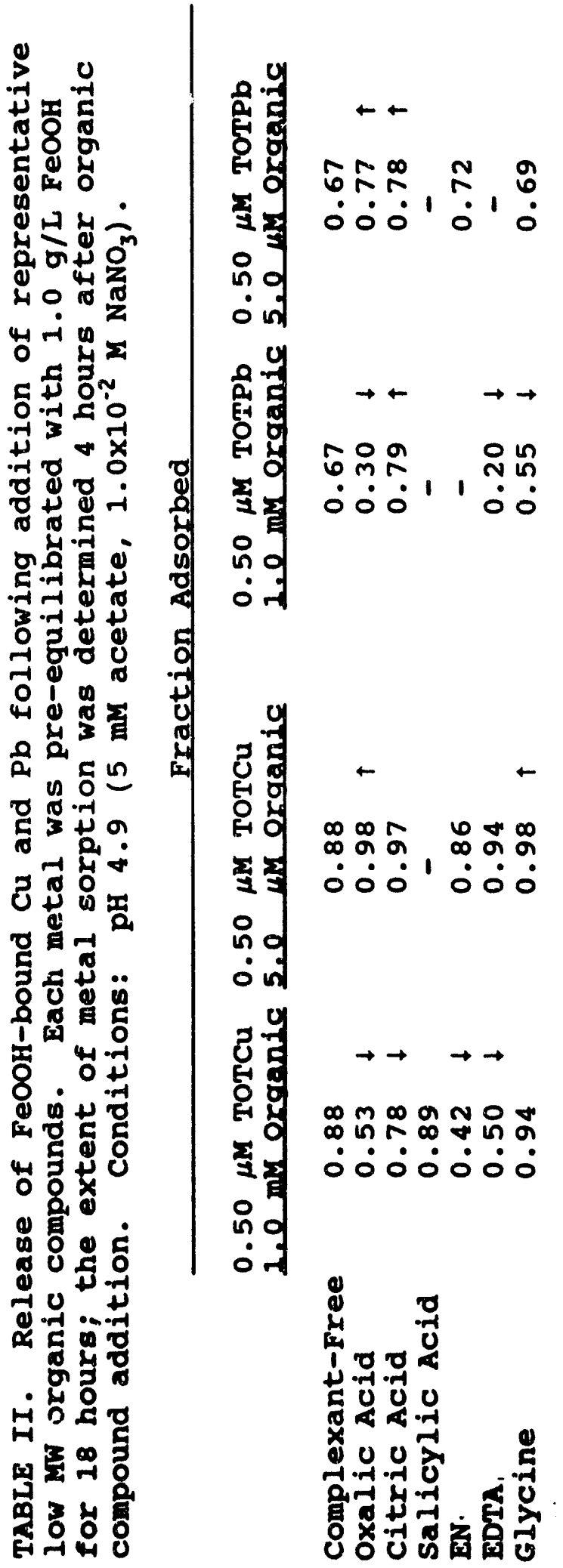



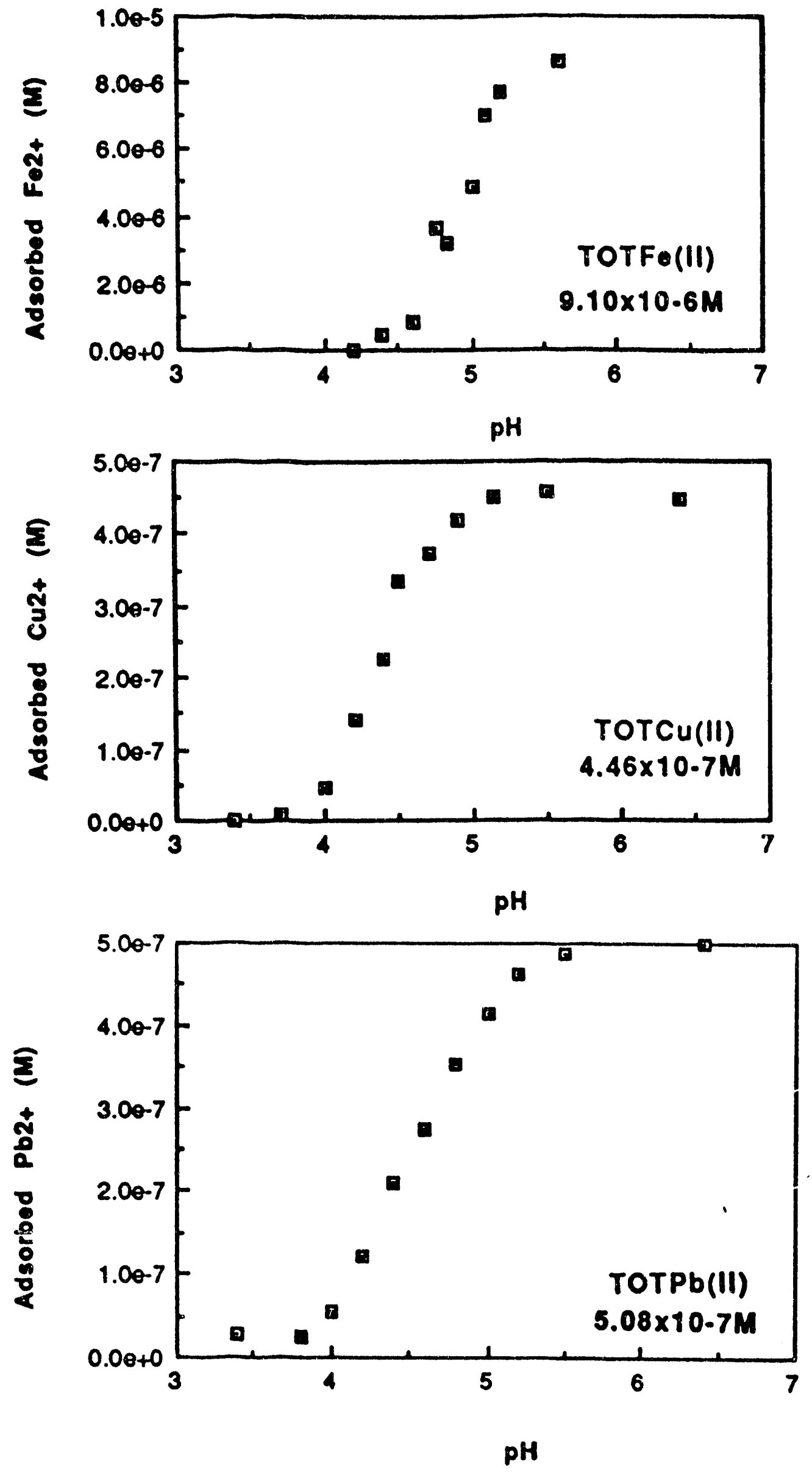

- FIGURE 2. Adsorption of $\mathrm{Fe}(\mathrm{II}), \mathrm{Cu}$, and $\mathrm{Pb}$ in $1.0 \mathrm{~g} / \mathrm{L} \mathrm{FeOOH}$

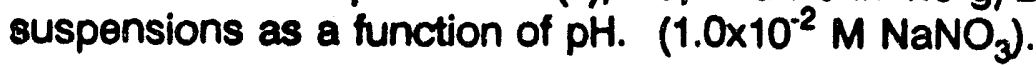



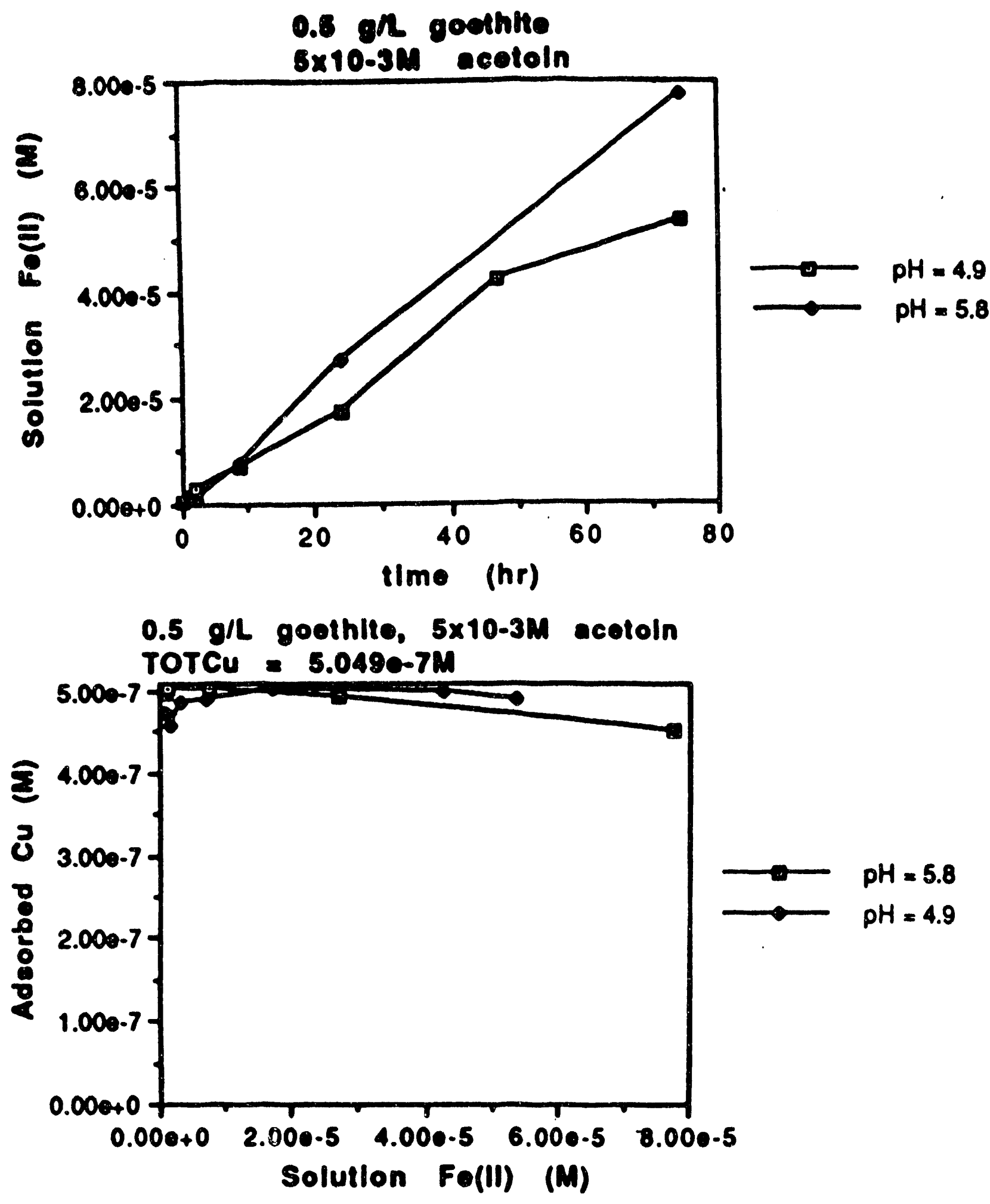

FIGURE 3. Reductive dissolution of $0.5 \mathrm{~g} / \mathrm{L} \alpha-\mathrm{F} \theta O O H$ by $5.0 \mathrm{mM}$ acetoin. Cu was equilibrated with the FeOOH sample for 18 hours before addition of reductant. After 75 hours of reaction with acetoin, no Cu(II) desorption was detected (5.0 mM acetate buffer, $10.0 \mathrm{mM} \mathrm{NaNO}$ ).

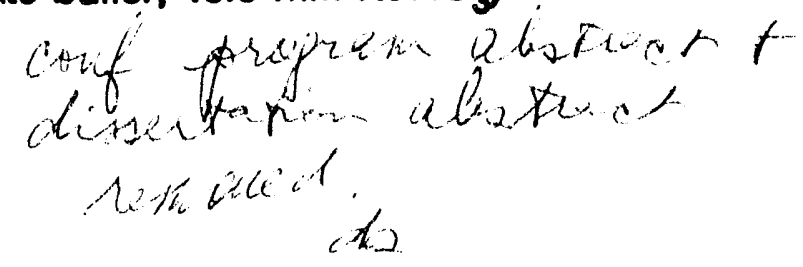



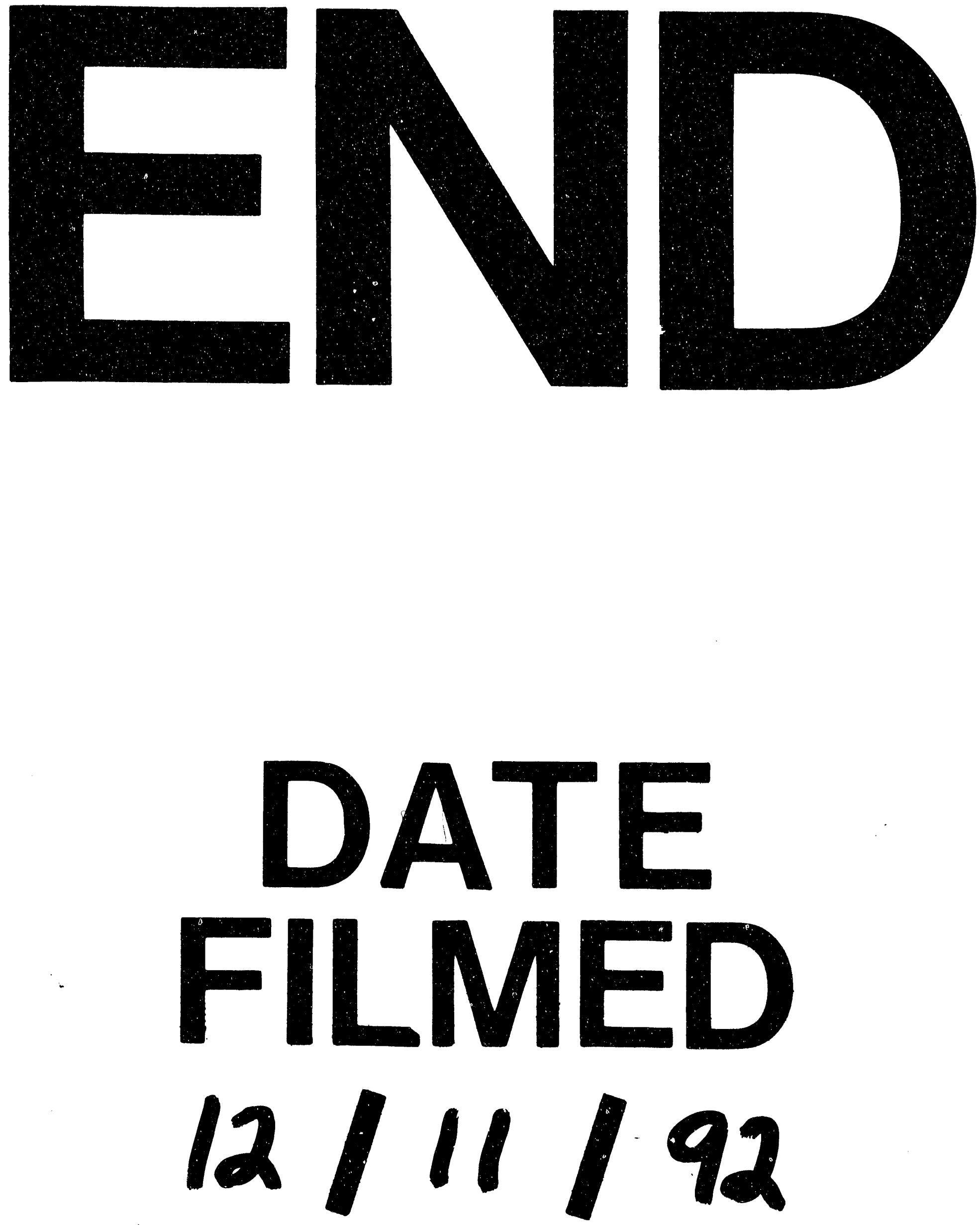
